Interview

For reprint orders, please contact: reprints@futuremedicine.com

\title{
What could the future hold for treatment sequencing in cancer medicine? An interview with Angela Märten
}

\author{
Angela Märten ${ }^{*, 1} \&$ Rachel Jenkins ${ }^{2}$ \\ ${ }^{1}$ Boehringer Ingelheim, TA Oncology Medicine, Binger Strasse 17355216 Ingelheim am Rhein, Germany \\ ${ }^{2}$ Unitec House, Albert PI, Finchley, London, N3 1QB, UK \\ *Author for correspondence: angela.maerten@boehringer-ingelheim.com
}

Professor Angela Märten speaks to Rachel Jenkins, Commissioning Editor: Angela Märten earned her PhD at Humboldt University of Berlin, Germany, in 2000, after working for several years as an oncology nurse. Upon completion of her PhD, she assumed responsibility for Phase I trials and translational research for the University Hospital of Bonn, Germany. In 2002, the University Hospital of Bonn appointed her as Assistant Professor for Experimental Haematology and Oncology. In 2003, she accepted a new position at the University of Heidelberg, Germany, heading the Immunotherapeutic Group and the Oncology Trial Department. The University of Heidelberg appointed her as Associate Professor in 2006 while she completed her Master of Sciences in Clinical Research in 2008. Professor Märten has been principal investigator of several clinical trials and has published more than 100 papers, with a particular focus on pancreatic carcinoma and lung cancer. She joined Boehringer Ingelheim in 2009, where she built up the German Medical Affairs Oncology team, before joining the Global Afatinib team in 2013. She is currently Global Senior Medical Advisor, Therapeutic Area of Oncology at Boehringer Ingelheim.

First draft submitted: 27 March 2019; Published online: 19 August 2019

Keywords: non-small-cell lung cancer • oncology • scientific research • sequencing • testing

\section{Please introduce yourself to our readers \& tell them about your career to date}

I have been interested in oncology since I left school - first becoming an oncology nurse, then moving into scientific and clinical research studying immunological and molecular aspects of oncology. I completed my PhD, which investigated the use of immunotherapy for gastrointestinal tumors, at Humboldt University, Berlin, Germany, and was appointed Associate Professor at the University of Heidelberg, where I led the Immunotherapy Group and the Surgical-Oncological Trial Department. I joined Boehringer Ingelheim 10 years ago, heading the new and growing Medical Affairs Oncology team in Germany before becoming Global Senior Medical Advisor Oncology in 2013 .

What does your current role as the Senior Global Medical Advisor Oncology for Boehringer Ingelheim involve?

This is a varied, multi-faceted role and my responsibilities include interpretation and analysis of clinical trial data and putting them into context in the treatment landscape. I am also deeply involved in the planning and conducting of studies like real-world studies and compassionate use programs as well as publications. The overarching theme is scientific communication, both within Boehringer Ingelheim and with external stakeholders including clinicians and researchers. Importantly, my role facilitates a communication exchange. A major part of my role comprises listening to the views and real-world experiences of clinicians and getting their input on future activities, for example, at congresses, steering committee meetings and advisory boards. This engagement is as important as discussing new data.

Future Medicine 
Recently, you were author on the Future Oncology Research Article 'Sequential treatment with afatinib and osimertinib in patients with EGFR mutation-positive non-small-cell lung cancer: an observational study'. What would you like the reader to take away from the paper?

Treatment of EGFR mutation-positive NSCLC has changed markedly over recent years with three generations of tyrosine kinase inhibitors (TKIs) now being available for many patients. However, as yet, little research has assessed whether patient outcomes can be optimized with sequential use of the available agents. The observational GioTag study demonstrated encouraging outcomes in 204 patients who received the second-generation ErbB family blocker afatinib, followed by the third-generation EGFR TKI osimertinib after developing the T790M EGFR mutation [1]. In these patients, the median duration of treatment was 28 months (and nearly 4 years in Asian patients), thus demonstrating the potential of sequential TKI regimens to prolong chemotherapy-free treatment for almost unprecedented periods of time in EGFR mutation-positive NSCLC.

As well as being the largest study, to date, to assess sequential therapy in NSCLC, GioTag has two important implications for the oncology field in general. First, in an era of rapid progress in the development of targeted agents and an increased focus on patient-specific precision medicine, it illustrates the need to optimize sequential treatment according to the tumor biology of individual patients over the course of the disease. Second, it showcases the value of observational real-world studies in oncology and how such studies can complement randomized clinical trials.

\section{Since the start of your career, how have you seen research into treatment sequencing for NSCLC evolve?}

Well, at the start of my career, treatment sequencing was not an option for NSCLC owing to the lack of effective treatments other than chemotherapy. Recent scientific research into the biology of tumors has enabled the development of targeted therapies, resulting in so many more treatment options and, importantly, enabling personalized and scientifically validated treatment. Research is now focused on the identification of resistance mechanisms and assessing whether particular patient subgroups derive superior benefits from specific treatment. Rapid progress in these areas is enabling the sequencing of contemporary therapies to optimize patient outcomes.

\section{What would you consider to be the greatest challenges hindering this research $\&$ how do you think we may be able to overcome them?}

A key challenge is testing. Cancer centers need to have the routine capability to identify mutations and biomarkers over the course of the disease in individual patients. This requires ongoing development of, and access to, sensitive standardized assays in the clinic that reflect progress in the understanding of tumor biology $[2,3]$. Such technological developments are important to ensure that scientific advances are incorporated into everyday clinical practice.

\section{Leading on from the challenges, what developments do you think are possible in the next 5-10 years regarding treatment sequencing in cancer medicine?}

With the costs of technologies such as liquid biopsies and next-generation sequencing decreasing, I would expect that more personalized treatment sequencing options are available for each and every patient.

\section{Are there any final comments that you have for the readers of Future Oncology?}

In addition to the development of new treatments, new study designs are needed to provide a more complete picture of a drug's effectiveness. For example, as randomized clinical trials necessarily include selected patient populations, oncology treatment could be advanced by an increased use of real-world evidence [4], thus complementing clinical trial data and providing a broader compendium of information to inform rational treatment choices.

\section{Disclaimer}

The opinions expressed in this interview are those of the interviewee and do not necessarily reflect the views of Future Medicine Ltd. 
Financial \& competing interests disclosure

A Märten is an employee of Boehringer Ingelheim GmbH. The authors have no other relevant affiliations or financial involvement with any organization or entity with a financial interest in or financial conflict with the subject matter or materials discussed in the manuscript apart from those disclosed.

No writing assistance was utilized in the production of this manuscript.

\section{References}

1. Hochmair MJ, Morabito A, Hao D et al. Sequential treatment with afatinib and osimertinib in patients with EGFR mutation-positive non-small-cell lung cancer: an observational study. Future Oncol. 14, 2861-2874 (2018).

2. Ellison G, Zhu G, Moulis A et al.EGFR mutation testing in lung cancer: a review of available methods and their use for analysis of tumour tissue and cytology samples. J. Clin. Pathol. 66, 79-89 (2013).

3. Horak P, Fröhling S, Glimm H. Integrating next-generation sequencing into clinical oncology: strategies, promises and pitfalls. ESMO Open 1, e000094 (2016).

4. Blonde L, Khunti K, Harris SB, Meizinger C, Skolnik NS. Interpretation and impact of real-world clinical data for the practicing clinician. Adv. Ther. 35, 1763-1774 (2018). 